\title{
O serviço de recreação operária e o projeto de conformação da classe operária no Brasil
}

Elza Peixoto*

\begin{abstract}
Resumo: $N$ as décadas de20/30/40 do século XX foram realizadasno Brasil diversas experiências derecreação pública voltadas para os operáriose seusfamiliares. Estetrabalho revisa ediscuteos fundamentos da experiênciaimplementadano D istrito Federal na década de 1940, recorrendo à análise do projeto de recreação para trabal hadores efilhos detrabalhadores, elaborado pelo Governo de G etúlio Vargas, através do M inistério do Trabalho, Indústriae Comércio (M inistro M arcondes Filho) e do Serviço de Recreação O perária - S.R.O. (Arnaldo Sussekind). Esta análise é efetuada com base em relatórios, em entrevistasena produção deArnaldo Sussekind, reconhecido aqui como intelectual orgânico declasse Conclui-se, como primeirosapontamentos, quea recreação compõea política de conformação da classeoperária implementada em todo o mundo e, especificamente, no Brasil; equeo S.R.O é parte dessa política de conformação.
\end{abstract}

Palavras-chave: recreação; estudos do lazer; conformação; trabalho; classeoperária.

Abstract: In the 20s, 30s and 40s, several experiences of public recreation for workers and their families were implemented in Brazil. This paper reviews and discusses the principles of the experience implemented in the Federal D istrict in the 40 s, drawing on the analysis of the recreational project for workersand their children prepared during G etúlio Vargas' government, by the M inistry of Labor, Commerceand Industry (M inister M arcondesFilho) and the Working ClassRecreation Service(Arnaldo Sussekind). This analysis sis based on reports, interviews and theproduction developed by Arnaldo Sussekind, who is recognized asan organic classintellectual. Just likein the first records, it is concluded that recreation makesup theworking class constitution policy implemented worldwideand, specifically, in Brazil, and that theW orking Class Recreation Service(WCRS) is part of this constitution policy.

Key words: recreation; leisurestudies; constitution; work; working class.

Introdução

U ma das condições fundamentais para a expansividade do capitalismo éa integração das classestrabal hadoras à sua ordem.

\footnotetext{
* Professora do Centro de Educação Física e Desportos - CEFD da Universidade Estadual de
} Londrina - UEL. emmpeixoto@yahoo.com.br 


\begin{abstract}
0 confronto entreas classes, ocorrido com radicalidadeno século XX, obrigou o capital a adotar medidas decontratendênciaque pudessem conformar as classesà sua condição de subalternidade - condição queéperseguida constantementepelo capitalismo. A Revolução Russa, mesmo com todas as limitações observadas no decorrer da experiência soviética, inaugurou um aspecto nunca antesassumido, no antagonismo existenteentreasclasses fundamentais. A forma estatal experimentada com 00 utubro de 1917 materializou o antagonismo, de modo quea alternativa socialista passou a apresentar-se como realidadeconcreta, como possibilidade de implementação de uma nova hegemonia, na medida em que, conforme Gramsci, "os proletáriosnão fazem a lutade classes somente paraaumentar os salários, mas sobretudo para substituir pela própria classe que trabalha aquela dos capitalistas quea fazem trabal har" (Braga, 2005, p. 29).
\end{abstract}

A virada do século XIX para o XX foi marcada pela intensificação das crises por que passou o capitalismo na Era dos Impérios - 1875/1914 - (H obsbawm, 2003), caracterizadas por ciclos de queda das taxas de lucro e de planos de reestruturação da produção com vistas à sua retomada. 0 século iniciou-se com o reordenamento geopolítico do mundo, fundado em conflitos cujo ápice foi a Primeira Guerra M undial (1914) e que iriam desenrolar-se por todo o B reve Século XX (H obsbawm, 1995). Ao mesmo tempo, o movimento operário expandiu-se e intensificou-se no passo do desenvolvimento industrial, organizando-se na I e II Internacionais Comunistas. Em 1917 a Revolução Russa materializou o temor burguês quanto à expansão do comunismo, polarizando os conflitos que iriam caracterizar cerca de 68 anos do século XX (1917-1985). A burguesia reorganizou as bases para a manutenção de sua hegemonia, implementando os métodos "taylor-fordistas", cuja meta central era a adaptação do trabalho humano às necessidades do capital, além da reformação do trabalhador com vistas à contenção da luta de classes (Braga, 2005).

0 século XX, no Brasil, caracterizar-se-ia pelo processo de consolidação da burguesia, que, de modo particular, necessitava controlar os setores conservadores e a classe trabal hadora. 0 s embates com os setores conservadores foram resolvidos através de acordos político-econômicos (Braga, 2005, p.59-69). 0 embate com a classe trabalhadora foi encaminhado através de um amplo projeto de contenção das lutas de classe que explodiram em toda a década de 1920 (Franco, s/d; Weinstein, 2000) e de conformação dos interesses dos trabalhadores aos interesses burgueses. Esse projeto foi empreendido através de ações que envolveram a estruturação de uma legislação trabal hista nos moldes do primeiro mundo, passando pela reestruturação da educação e da formação da classe 
trabalhadora com base na racionalização taylor-fordista do trabal ho e do repouso, com predomínio da intenção de tutela do tempo livre: a modernização e a industrialização brasileiras dependiam deste movimento.

N esse contexto, configurou-se nas décadas de 20, 30 e 40 do século passado uma política de recreação em duas frentes: (1) ocupação e educação dos menores - com destaque para a "R ecreação Pública" promovida pela Prefeitura M unicipal de Porto Alegre (1926-1955) e para a experiência da "D ivisão de Educação e Recreio do Departamento de Cultura e Recreação" promovida pela Prefeitura Municipal de São Paulo (1935-1947); (2) ocupação do tempo livre do trabalhador - com destaque para a experiência do "Serviço de R ecreação 0 perária - S.R.O." implementada pelo Governo Federal através do M inistério do Trabalho, Indústria e Comércio (1943-1963)1․ N este texto, dedicamo-nos especificamente à observação da preocupação com o tempo livre do trabalhador, que iria configurar um projeto de educação para e pela recreação. A nosso ver, a obra de Arnaldo Sussekind, que aborda a experiência do S.R.O . implementada no DF na década de 1940, expressa as características da preocupação burguesa com a ocupação do tempo livre do trabalhador no Brasil com vistas à conformação da classe trabalhadora aos interesses da burguesia.

A presentamos a seguir os fundamentos desta política pública, neste que estamos chamando de primeiro ciclo da produção do conhecimento referente aos estudos do lazer no Brasil. D estacamos as conexões entre (1) o projeto produzido, implantado e conduzido por Sussekind; (2) as preocupações e os temores internacionais quanto ao "fantasma" socialista que assolava o mundo2; (3) os interesses das elites industriais brasileiras. Para tanto, recorremos à citação

1. A exposição detalhada sobre estas experiências encontra-se em Gomes (2003), que as associa, respectivamente, às trajetórias de Frederico Guilherme Gaelzer; Mário de Andrade (18931945) e Nicanor Miranda (1907-?); e Arnaldo Sussekind (1917). Preferimos trabalhar com a noção de intelectual orgânico de classe desenvolvida por Braga (2005). Assim, longe de atribuir um projeto de classe a um indivíduo, como entendemos ter sido feito por Gomes em seu estudo, desejamos captar, no discurso do intelectual gestor desta política, o projeto da classe burguesa - seus fundamentos, suas argumentações e finalidades.

2. Mascarenhas (2005, p. 96-97) informa: "Figurando na Declaração Universal dos Direitos do Homem, aprovada em 1948 pela Assembléa Geral da ONU, o lazer, assim como a saúde, educação, habitação etc., passam a adquirir o status de direitos sociais básicos. Deste modo, a engenharia política capitalista permitiria, durante um bom tempo, a convivência pacífica entre crescimento da economia, ampliação do consumo dos assalariados e garantia dos direitos, recompondo a estabilidade do sistema. Antes mesmo desta época, ao passo que o descanso de final de semana e as férias remuneradas já adquiriam base legal, fazia-se necessário indicar 0 modo como as horas de lazer do trabalhador deveriam ser utilizadas. Interessante notar, segundo registram Sussekind, Marinho e Góes (1952), que a Conferência Internacional do Trabalho, em 1924, o Congresso Internacional de Lazeres Operários, em 1930, e a reunião do comitê assessor do Conselho de Administração da OIT para a questão dos lazeres operários, em 1938, 
literal de trechos das entrevistas concedidas pelo jurista à Revista Prática Jurídica (2004); ao informativo N otícias do Tribunal Superior do Trabalho (2002); à R evista Estudos H istóricos (1993); e a G omes (2003b). Além desses depoimentos, recorremos também às obras publicadas pelo autor (Sussekind, 1946, 1950).

$N$ asci no Rio de Janeiro em 9 de julho de 1917, filho do magistrado F rederico Süssekind e Sylvia Lopes Süssekind. A carreira do meu pai, que chegou a desembargador do Tribunal de Justiça e a ministro do Supremo Tribunal Eleitoral, influenciou, sem dúvida, a minha decisão de ingressar na Faculdade N acional de Direito da Universidade do Brasil, sediadana então C apital Federal. [...] Fui admitido no Conselho $\mathrm{N}$ acional do Trabalho, como auxiliar de escrita, em janeiro de 1938. U m ano depois passei a subassistentetécnico e, em 1940, já bacharel, fui nomeado assistentejurídico. N o exercício desse cargo elaborava parecer nos pedidos de avocatória para 0 M inistro do Trabalho, Waldemar Falcão, o qual, ao ser instalada a) ustiça do Trabal ho em 1941, entendeu de justiçaindicar-me para o cargo deProcurador Regional do Trabalho da 2 ${ }^{a}$ R Região, com sedeem São Paulo (Sussekind, 2004, p. 6-9).

Atualmente jurista conceituado no campo do direito do trabalho, Sussekind participou em 1942 da comissão que elaborou a Consolidação das Leis do Trabal ho (C.L.T.). Em entrevista concedida à revista Estudos $\mathrm{H}$ istóricos, $\mathrm{O}$ autor relatou o processo de sua inclusão naquela Comissão:

0 ministro Alexandre $M$ arcondes Filho foi nomeado para a pasta do Trabalho, Indústria eC omércio no dia 2 dejaneiro de 1942 eme chamou para ser um dos seus assistentes. $N$ ão que eu fosseconhecido. N inguém sabiaquem era Arnaldo Sussekind. Eu havia entrado parao M inistério do Trabalho como estudante de direito na função de auxiliar de escrita, depois passei a assistentetécnico, depoisa assistentejurídico efinalmente, com a criação da Justiça do Trabalho, fui nomeado chefe da ProcuradoriaR egional do Trabalho em São Paulo. 0 ministro quis prestigiar a Procuradoria de São Paulo eme trouxe como seu assistente.

já esboçavam algumas indicações a fim de se guiar os trabalhadores para o correto emprego de seu tempo livre, mas é somente em 1949, por ocasião da Conferência de Técnicos em Recreação do Comitê de Correspondência da OIT, que algumas recomendações começam a ser bem mais detalhadas". Nesse sentido, a contribuição de Sussekind ultrapassa os interesses nacionais, na medida em que apresenta à OIT os progressos da política de recreação implementada (o que não quer dizer universalizada) no Brasil já em 1946. Ver também Sussekind (1950, p. 555-580). 
D esde logo o ministro $M$ arcondes manifestou a idéia de consolidar a legislação do Trabalho e da Previdência Social, porque naquela ocasião havia uma multiplicidade de leis de distintasfasespós-Revolução de 1930, al gumasatéantagônicas, além de omissões importantes, e era preciso ordenar a coisa sistematicamente. Preparou-se então uma portaria designando uma comissão de dez membros, sob a presidência dele, $M$ arcondesFilho, parafazer aConsolidação das Leis do Trabalho edaPrevidência Social. Essa portaria foi publicadano dia 29 de janeiro de 1942, com a concordância do presidente da República, Getúlio Vargas, quehavia autorizado a consolidação. M as na primeira reunião, os membros da comissão mostraram ao ministro quetinham queser feitas duas consolidações, uma do Trabalho, outra daPrevidência. O sgruposforam separados, ea comissão encarregada de fazer aC.L.T. foi constituída pelos procuradores da Justiça do Trabalho Luís Augusto de Rego $\mathrm{M}$ onteiro, então diretor geral do $\mathrm{D}$ epartamento $\mathrm{N}$ acional do Trabal ho, D orval Lacerda, José de Segadas V iana, que mais tardefoi ministro do Trabalho de G etúlio Vargas, eeu, além do consultor jurídico do M inistério O scar Saraiva. Isso explica por que, com 24 anos, integrei esse grupo: eu era assistente do ministro, e ele queria ter uma pessoa de trato cotidiano na comissão, para lhe dizer o queestava sendo feito, combinar as coisas com eleetc. D epois, Rego M onteiro eeu fomos diversas vezes ao presidente G etúlio Vargas, junto com o ministro $M$ arcondes, para explicar as inovações. M arcondesfazia questão dequeG etúlio autorizasseasinovações quefossem feitas (G omes; D 'Araújo, 1993, p.113).

Posteriormente, Sussekind ocupou os cargos de M inistro do Trabalho e Previdência Social no governo do General C astelo Branco (1964-1967) e M inistro do Tribunal Superior do Trabalho. As principais alterações realizadas na C.L.T. em 1967 (Governo de Castelo Branco, M inistro Jarbas Gonçalves Passarinho) e 1974 (G overno de Ernesto G eisel, M inistro Arnaldo da Costa Prieto) contaram com sua colaboração (G omes; D 'Araújo, 1993). Além desses cargos e atuações públicas, o jurista participaria das Conferências Gerais da OIT, na condição de conselheiro, nos anos de 1951, 1952, 1953 e 1954, das nove conferências seguintes como delegado e de duas conferências como chefe de delegação. Entre 1970 e 1975, Sussekind foi eleito "como jurista independente, para a Comissão de Peritos na Aplicação de Convenções e Recomendações", tendo voltado a exercer este mandato entre os anos de 1982 e 1990, "depois de representar 0 Brasil no Conselho de Administração desta entidade". O s depoimentos do jurista permitem concluir uma estreita ligação entre a preocupação brasileira 
com os direitos trabalhistas, a criação do S.R.O . e a política internacional definida pela OIT, demonstrável pelo envio freqüente de delegações àquele evento. 0 conjunto da trajetória pública desse bacharel em direito confirma a facilidade com que transitava entre os diferentes governos no período compreendido entre as décadas de 1930 e 1990. Suas posições são públicas, havendo freqüentes consultas a esta autoridade no campo do D ireito do Trabal ho, quando 0 assunto se refere a qualquer alteração na C.L.T. Por esta razão, em entrevista concedida à Revista Prática Jurídica (2004), o autor discorreu sobre 0 que representou a C.L.T. ${ }^{3}$ para o Brasil e sobre a necessidade de atualizações:

A C.L.T. [...] ampliou e consagrou direitosfundamentais do trabalhador e concorreu para o sucesso da industrialização do País.

$\mathrm{N}$ uma das vezesqueacompanhei o $\mathrm{M}$ inistro $\mathrm{M}$ arcondesFilho para explicar ao presidente certas inovações que se pretendia sugerir no anteprojeto, G etúlio sublinhou que, a seu ver, a complementação do sistema legal trabalhista atenderia aos objetivos dejustiça social da Revolução de 1930, exerceriauma função educativa das leis que se antecipam aos fatose evitaria que, terminada a guerra em curso, eclodissem greves talvez violentas, reivindicatórias de novos direitosque, certamente, atrasariam a desejada industrialização. N essa oportunidade $M$ arcondes lembrou que, para consecução desse objetivo, no mesmo período, ele (G etúlio) criariaa CompanhiaValedo Rio D oce, paraextrair o ferro; eaC ompanhiaSiderúrgica $N$ acional, paratransformállo em aço; o Senai, para profissionalizar osjovens na atividade industrial; e, no mesmo contexto, estava promovendo a uniformização e ampliação dos direitos trabalhistas (Sussekind, 2004, s/p).

Em outra entrevista, o jurista, após nomear as leis existentes antes da Consolidação, depôs sobre os temores de Vargas:

Q uem mais legislou foi realmente Getúlio. N ão foi uma legislação conquistada debaixo para cima. Ela veio decima para

3. Nesta mesma entrevista, Sussekind informa os objetivos perseguidos pela comissão que estruturou a C.L.T.: "[...] o objetivo do Ministro Marcondes, logo autorizado pelo Presidente Getúlio Vargas, era o de juntar numa só lei, corrigindo algumas normas superadas e certos antagonismos: a) os decretos legislativos de 1930 e 1934; b) as leis do Congresso Nacional até 10 de novembro de 1937 ; c) os decretos-leis do período subseqüente. A Consolidação alcançaria as disposições concernentes ao Direito do Trabalho e à Previdência Social". O jurista explica as razões que levaram à constituição de duas comissões, uma que trataria da consolidação e a outra que trataria da previdência, informando ter sido assessor especial do senado para a elaboração de Lei Orgânica uniformizando o sistema em 1960 (Sussekind, 2004). 
baixo, foi o quesechamou de outorga da legislação. E isso foi feito com uma dupla intenção. A primeira eramesmo evitar que lutas sangrentas viessem a ser travadas para conquistar leis. $N$ ós tínhamos o exemplo de algumas greves importantes de anarquistas, sobretudo em São Paulo, mas também no Rio, Bahia, Pernambuco, Rio Grandedo Sul, decorrentes deuniões fabriscriadas por influência deimigrantes italianoseespanhóis. Getúlio temiaosmovimentosviolentos, como os queocorreram na Europa eem alguns países como o M éxico ea Argentina. A segunda preocupação dele era criar um clima favorável à industrialização do país. Essesforam dois pontosqueelesempre pretendeu atingir (Sussekind, apud G omes; D 'Áraújo, 1993).

A respeito das referências que nortearam a estruturação da C.L.T. brasileira, com destaque para o trecho no qual 0 autor informa a influência das $C$ onvenções da O IT na C.L.T., disse:

Asfontes materiais do texto consolidado foram as conclusões do $1^{\circ}$ Congresso Brasileiro deD ireito Social (São Paulo, 1941), as convenções da O IT, aencíclicaRerum N ovarum eospareceres do Consultor Jurídico do M inistério O liveira Viana e do seu sucessor O scar Saraiva. Q uanto à "C arta D el Lavoro", acredito que $99 \%$ das pessoas queafirmam, por ignorância, queaC.L.T. é uma cópia dela, na verdade nunca a leram. A Carta de M ussolini possuía apenas 17 itens sobreo D ireito do Trabalho, consagrando princípiostradicionais(justo salário, adicional de trabalho noturno, repouso semanal, férias anuais, indenização por despedida injusta, sucessão empresarial, contrato de experiência, trabalho a domicílio e poder hierárquico do empregador) e instituições já adotadas em outros países (unicidade sindical e tripartismo). É certo que M ussolini conspurcou o sindicato único para cada categoria profissional, mas não menos certo éque dez anos anteso respectivo sistema fora adotado pelaU nião Soviética. Trata-sedeum princípio de direito sindical, bem ou mal, enão deum princípio comunista ou fascista que, surpreendentemente, foi mantido pela Constituição de 1988 com disposições similares às da C arta Política de 1937. Com relação ao tripartismo nos órgãos julgadores, arbitraisou conciliadores dos litígiostrabal histas, ele já vigorava em al guns países, sendo consagrado, atéhoje, pela O rganização Internacional do Trabalho (Sussekind, 2004).

Em 2004, consultado sobre o papel histórico da C.L.T. e se seu ciclo se havia encerrado, Sussekind respondeu: 
- É evidente - como acabamos de acentuar - que a C.L.T. cumpriu papel histórico de rel evo nas rel ações detrabalho em nosso País. M aso mundo mudou, sobretudo em conseqüência da globalização da economia resultante da evolução tecnológica acelerada, da implosão do império soviético edo consenso de Washington. Países e empresas procuram reduzir custos para melhorarem sua posição no mercado internacional. $\mathrm{N}$ aEuropa, como registrou recente relatório da OIT, a preocupação é aumentar a produtividadepelaflexibilização dealgumasnormas aplicadas às relações de trabalho, o quetem proporcionado 0 crescimento médio anual de $0,16 \%$ da respectiva taxa, atéo sétimo ano deemprego, quando então estaciona em relação a cada trabal hador. $\mathrm{N}$ a América Latina, inclusive no Brasil, 0 caminho preferido éo da redução dos direitostrabal histas. Para osneoliberais mais radicais, com o apoio de parteda mídia, 0 desejável seria a desregulamentação, como se fosse possível romper com atradição romano-germânica do nosso $D$ ireito. $E$ culpam a C.L.T. pelo elevado custo dos encargos sociais, esquecidos, por ignorância ou máfé, queeles correspondem à inadequada incidência na fol ha de salários das contribuições para a Previdência Social, o sistemaS (Sesi, Sesc, Senat, Senai, Senac), o Sebrae, o Incraeo salário-educação. N ão somos contra as referidas entidades, que têm prestado bons serviços, mas é preciso encontrar outra base de incidência. $E$, para os que insistem em criticar a "EraVargas", cumpreregistrar queosmais elevados encargos trabal histas não foram criados ou adotados pelaC.L.T.

AsrevisõesdaC.L.T. de1967 (C astelo Branco) e1977 (Geisel) foram oportunas. Contudo, a meu ver, a C.L.T. esualegislação complementar carecem de atualização, a fim de que seja permitida (sic!), por meio da negociação coletiva, flexibilizar a aplicação de normas legais acima do nível de proteção irrenunciável, visando à implementação de nova tecnologia ou novos métodos de trabalho, ao atendimento de peculiaridades regi onais sou à preservação da saúde da empresa edos respectivos empregos. Isso complementaria a ampla flexibilização, propositadamenteesquecida pelosneoliberais, quejá vigora no Brasil: liberdade patronal para despedir empregados(FGTS), redução salarial por convenção ou acordo coletivo; flexibilização dasjornadas detrabalho; contrato detrabalho provisório com redução de direitos; trabalho a tempo parcial etc. (Sussekind, 2004, s/p).

A respeito da OIT, a cujo tema se dedicou em um de seus trabalhos, discorreu 0 autor: 
A Conferência G eral da O IT, que se realiza anualmente em G enebra, além de outras atribuições, adota as convenções e recomendações internacionais do trabalho. [...]

A OIT foi criada em 1919 pelo Tratado de Versailles para universalizar os princípios nele consagrados. E o seu desempenho foi tão auspicioso que, após a G uerra de 1939 1945, foi o único organismo internacional que, tendo pertencido à extinta Liga das $\mathrm{N}$ ações, passou a integrar afamília das $\mathrm{N}$ ações $U$ nidas.

Até 1960, a O IT adotou, preferentemente, convenções de caráter regulamentar, as quais não precisam de leis nacionais para sua aplicação nos países que as retificam desde que consagrem, como a maioria, o sistema monista deintegração do tratado no direito interno. D epois queseaprofundou 0 abismo entre os Estados plenamente desenvolvidos, os em vias de desenvol vimento e os subdesenvolvidos, a Conferência passou a aprovar convenções de princípios, salvo em se tratando de direitos humanos fundamentais, como trabalho forçado, liberdade sindical, discriminação no emprego, idade mínima para o trabalho etc. E ampliou os programas de cooperação técnica visando, principal mente, ao acatamento a esses direitos. Atualmente, a O IT tem dado ênfase àimplantação detrabalho decente e à abolição das piores formas de trabalho infantil (Sussekind, 2004, s/p).

O s trechos aqui relacionados contribuem para que percebamos as conexões entre a preocupação dos líderes mundiais com a regulamentação do trabal ho expressa na instalação e nas Convenções da OIT - e a Legislação que, sob influência desta organização, seria implantada no Brasil a partir de 1930. É visível a clareza do projeto de Getúlio Vargas exposta nestes depoimentos do jurista. A incursão por Weinstein (2000) permitirá reconhecer nestas passagens o discurso de uma parte da burguesia brasileira, especialmente daquele segmento preocupado com a industrialização e a modernização do Brasil.

O s conflitos que marcaram a formação da burguesia no Brasil possibilitaram constatar que evitar lutas sangrentas não foi tarefa fácil, visto a resistência de setores que não concordavam com a implantação de legislação tão "avançada". Sabemos, com base em Hobsbawm (1995) e Weinstein (2000), que o modo como a URSS sobreviveu à G rande D epressão assombrou o mundo capitalista, levando-o a um grande pacto social que culminou com os Estados do Bem-Estar, estruturados na segunda fase (décadas de 1960 e 1970) daquela que H obsbawm chamaria de Era do 0 uro (décadas de 1950 e 1960). O s depoimentos do jurista confirmam essas alusões históricas. 
O s apontamentos a seguir permitirão levantar elementos para a percepção da conexão entre o projeto de "neutralizar a luta de classes prevista por Karl M arx" (Simonsen, apud Weinstein, 2000, p.88) e o projeto de "conformar a classe trabalhadora aos interesses da burguesia nacional na modernização e na industrialização do Brasil" (Weinstein, 2000; Braga, 2005).

\title{
Arnaldo Sussekind e o Serviço de Recreação Operária
}

Em 1943, o M inistro M arcondes Filho nomeou uma comissão para a elaboração do Projeto de S.R.0.4. 0 artigo $7^{\circ}$ do decreto-lei n. 4.298, de 14 de maio de 1942, previa "a aplicação do imposto sindical em finalidades culturais e esportivas". Com vistas à "melhor consecução dos objetivos visados pelo legislador", a portaria no 68, que instituiu o S.R.0. no dia 06 de dezembro de 1943, justificou a criação deste pela necessidade de um órgão "que coordene os meios de recreação da classe operária, prestando aos sindicatos sua assistência e colaboração", e que funcionaria "junto à Comissão T écnica de O rientação Sindical" (Sussekind, 1946, p.7). Perguntado sobre as razões que levaram 0 M inistro a nomear uma Comissão para estruturar o S.R.O., Sussekind respondeu:

\begin{abstract}
Por queeleachava queera importantepara os trabalhadores, dar (sic!) a possibilidade do lazer. 0 trabal hador, deum modo geral, não tinha recursos para lazeres, e então o objetivo do Serviço de Recreação 0 perária (não existia ainda o SESI eo SESC) seriafazer, nasvilasoperárias, criar um centro derecreação. Foi criado o Centro de recreação em Bangu, O laria, na Gávea, etc, etambém promover espetáculospara os trabal hadores (apud Gomes, 2003b, p.310).
\end{abstract}

A questão, no entanto, não era tão simples, nem recaía, como aparenta 0 discurso do jurista, sobre a vontade individual de Marcondes Filho. Um artigo

4. A portaria $n^{0} 52$, de 21 de setembro de 1943 , instalou a comissão que iria elaborar o Projeto do Serviço de Recreação Operária, sendo seu teor o seguinte: "O Ministro do Estado do Trabalho, considerando que se faz mister difundir cada vez mais as atividades físicas e morais entre a classe operária, facilitando-se-Ihes os meios de recreação em geral e prestando aos respectivos sindicatos a colaboração que for necessária, resolve designar os assistentes técnicos do seu Gabinete, Arnaldo Lopes Sussekind, Evaristo de Moraes Filho e Antonio Almeida Manhães, e Jelmires Belo da Conceição, como representantes dos Empregados Sindicalizados, para, em comissão, sob a presidência do primeiro, elaborarem projeto de portaria criando um serviço especial, junto à Comissão Técnica de Orientação Sindical, para 0 atendimento daqueles objetivos" (Sussekind, 1946, Fls. 7). A portaria n- 68 de 06 de dezembro de 1943 cria o Serviço de Recreação Operária, acatando na íntegra o projeto elaborado por esta comissão (Sussekind, 1946, p. 7) 
de Fábio Sodré (1938) expressou a posição desse liberal ligado à agricultura, setor no qual, claramente, havia resistência à legislação trabal hista implementada na década de 1930, considerada inadequada para a economia brasileira. 0 autor argumenta que a oferta e a procura de mão-de-obra estavam em relação inversa à economia européia, inspiradora das legislações em processo de implantação no Brasil, o que tornaria a legislação "avançada" e descontextualizada. A redução da jornada de trabal ho foi considerada por Sodré uma necessidade higiênica, nos casos de trabal hos que causam fadiga extrema, mas desnecessária nos casos em que não há fadiga no trabalho. Do mesmo modo, o acesso ao lazer foi reconhecido uma necessidade para os comerciários e contramestres de oficinas, mas uma "inutilidade" para "os nossos operários, cujo grau de cultura não permite aproveitar-Ihes os benefícios". 0 autor chegou a afirmar que grande maioria dos operários "prefere receber as férias em dinheiro, realmente para eles mais útil que o lazer concedido, mas que não sabem e não têm ainda como aproveitar" (Sodré, 1938, p.63-77). Disse 0 autor:

Certo deencontrar para cada operario quedespedir do emprego
dousou trêsáescolha parasubstituil-o, pódeo chefedeempreza
europeu desmandar-seem injustiças com o pessoal que dirige.
O mesmo já não sedáno Brasil, ondeescasseiaa mão deobrae
éraraa debôas qualidades. O bom operario não precisa aqui de
garantias legaes de estabilidade, pois que tem nanecessidade
dos seus serviçosa melhor das garantias. D esnecessaria, serviu a
nossa legislação nessepparticular apenas para levar a desordem
aos meios industriaes. G arantindo os máus elementos, os
indisciplinados, desestimulando os bons, áquelles equiparados,
contribuiu a lei para baixar o rendimento do trabalhador, com
todas as suas consequencias sobre o preço do custo, sobre o
preço de venda, sobre o nivel do consumo, repercutindo
finalmente sobreo mesmo salario em prejuizo do trabalhador
(Sodré, 1938, p.70).

Este texto evidencia (1) os conflitos que a burguesia teve de enfrentar, entre seus próprios pares, para a implementação do projeto burguês; (2) os conflitos entre capital e trabalho; (3) o medo dos burgueses brasileiros do comunismo5; e (4) uma idéia general izada entre as elites burguesas de que a classe trabalhadora não sabia usufruir o tempo livre que estava sendo reivindicado, em virtude da falta de educação. Seria este o argumento para a proposição de projetos educacionais diversos sob a promessa da conquista da alfabetização, da

5. Sodré argumenta contra a sindicalização, afirmando que a Intentona Comunista de 1935 só não obteve êxito em implantar o comunismo no Brasil porque a estrutura sindical aqui era inexistente e difícil de ser organizada (ver p. 72). 
qualificação profissional para a indústria e da qualificação para o "adequado" aproveitamento das horas de lazer, que tinham, entretanto, a clara intenção de conformação da classe trabalhadora aos interesses da burguesia industrial brasileira.

C ontraditoriamente, perguntado sobre a existência de relação entre a C.L.T. e o S.R.0., Sussekind respondeu negativamente (Gomes, 2003b, p.312). As evidências, no entanto, demonstravam haver clara relação entre a C.L.T., o Imposto Sindical e o S.R.O ., como podemos verificar no depoimento do jurista:

A 6 dedezembro do mesmo ano (1943) erainstituído no Brasil
o Serviço de Recreação O perária. A Portarian. 68, queo criou,
aprovara integral menteo projeto elaborado pela mencionada
Comissão. Como preâmbulo da Portaria, foi acentuado que "0
art. 7 do decreto-lei n. 4.298 , de 14 demaio de 1942, prevêa
aplicação do imposto sindical em finalidades culturais e
esportivas" eque, "para melhor consecução dosobjetivosvisados
pelo legislador, faz-se mister a instituiçãao de um órgão que
coordeneosmeiosderecreação daclasseoperária, prestando aos
sindicatossua assistênciaecolaboração" (Sussekind, 1946, p.7).

Apoiando-nos em Weinstein (2000), M arcassa (2002), Gomes (2003b) e Braga (2005), defendemos que a política de recreação implementada pelo G overno Vargas, através do M inistério do Trabalho, Indústria eC omércio conduzido por $\mathrm{M}$ arcondes Filho e do Serviço de Recreação O perária, conduzido por Sussekind, esteve associada de modo integrado ao projeto burguês de conformação da classe trabalhadora brasileira e de contenção da luta de classes, em um claro alinhamento com os movimentos internacionais nesta direção (H obsbawm, 1995) - o que não quer dizer que se constituísse em um consenso de classe, como demonstram os depoimentos do jurista, referentes às dificuldades decorrentes da falta de verbas ${ }^{6}$. Pelas razões relacionadas acima, seu pensamento sobre recreação merece toda a atenção dos estudiosos do lazer, uma vez que expõe as bases objetivas e ideológicas sob as quais se instalaram a industrialização e a formação da classe operária no Brasil. A obra de Sussekind concentra-se no âmbito do Direito do Trabalho, mas há um significativo número de textos dedicados a um projeto de recreação para a classe trabalhadora. Examinemos mais detidamente tais trabalhos.

6. "Pena é que as dotações orçamentárias consignadas para este Serviço não possibilitem a realização de excursões mensais, visto que as solicitações que, para esse fim, nos são dirigidas por sindicatos e os questionários preenchidos por operários comprovam a preferência por este tipo de recreação" (Sussekind, 1946, p. 29) 


\section{Justificativas para o Serviço de Recreação Operária}

O S.R.O . esteve sob a direção de Sussekind no período de 23 de maio de 1944 a 31 de dezembro de 1945. Em 30 de março de 1946, o jurista entregou 0 relatório de atividades desenvolvidas (Sussekind, 1946). N esse texto, publicado em um período de intensificação dos conflitos entre capital e trabal ho ${ }^{7}$, o jurista afirma ter procurado examinar os fundamentos sociais e psicofisiológicos do novo Serviço, sua organização e suas realizações. 0 jurista apóia-se na fisiologia, a fim de defender a necessidade de combate à fadiga, e na psicologia, a fim de defender o combate à apatia e ao desinteresse (Sussekind, 1946, p.19), vistos como ocasionados pelos progressos da produção baseada na maquinaria. 0 autor argumenta que o avanço da técnica "ultrapassou de muito o próprio desenvolvimento do organismo biológico humano", incapaz de adaptar-se "às novas condições sociais", o que resultou em "doenças nervosas de todas as espécies" (Sussekind, 1946, fls. 10-11).

Citando Alex Carrel, Sussekind diz que "O enorme avanço tomado pelas ciências da matéria inanimada sôbre as dos seres vivos é [...] um dos acontecimentos mais trágicos da humanidade". M as o autor não advoga "a eliminação da técnica moderna", conforme o faz Carrel. Ao contrário, o jurista defende o estímulo "ao progresso cultural da civilização, a fim de que os povos se adaptem às novas formas de vida material" (Sussekind, 1946, p.11). A poiado em W illiam 0 gburn, defende que:
[...] seo desajustamento entre o homem, como ser biológico, e a técnica, decorre do atraso da cultura em relação à técnica, cabenos, agora, criar egeneralizar uma cultura social equival ente àrealidade, paraque possamos controlála edirigi-la, usufruindo os benefícios materiais da sociedade sem prejuízo denossavida biológica (Sussekind, 1946, p.11).

O S.R.O . propunha-se a desenvolver um leque de atividades que permitissem a ocupação "sadia" do tempo livre do trabalhador, com o objetivo de recuperação fisiológica e psicológica da força de trabalho em busca do aumento da

7. Em levantamento na Biblioteca Otávio lanni (IFCH/Unicamp) localizamos, na revista Estudos Brasileiros, os artigos "Necessidades dos operários brasileiros" (Fábio Sodré, Estudos Brasileiros, ANNO I, N. 1, julho agosto de 1938) e "Três pesquisas de padrão de vida realizadas em São Paulo; Davis, Lowrie e Sta. Olímpia - Nível de vida dos operários na cidade de São Paulo" (Oscar Egídio de Araújo, Ano III, Volume 8, N. 22, janeiro-fevereiro de 1942). Este segundo relato refere-se à pesquisa do padrão de vida organizada pela Escola Livre de Sociologia e Política de São Paulo. Esses dados indicam uma preocupação crescente dos intelectuais orgânicos da burguesia com o conhecimento das condições vida da classe operária a fim de sobre ela estabelecerem maior controle. Ver a Dissertação de Braga (2005). 
produtividade. No relatório de Sussekind (1946, p.11) evidencia-se o entendimento de que o trabalhador possui "baixos" níveis de cultura, cabendo ao Estado promover a "elevação do seu nível de cultura" com vistas (1) à "compreensão dos fenômenos científicos, econômicos, sociais, políticos e artísticos"; (2) ao desenvolvimento das qualidades intelectuais do operário e do gosto pel os prazeres subjetivos. Assim, a educação do trabalhador torna-se-ia central para o bom aproveitamento do direito ao trabalho e ao descanso conquistado com a C.L.T. 0 autor diz claramente:

\begin{abstract}
D enada valeráo direito ao trabalho eao descanso para o operário analfabeto, ou simplesmente alfabetizado, porque não terá possibilidade de progredir no seu emprego, obtendo melhores salários, nem poderáutilizar suashoras derepouso com proveito para o seu espírito, visto queas formas mais sadias de recreação estarão sempresituadasnum plano quenão podeser alcançado pela sua inteligência restrita e ignorante. D e conseguinte, a recreação pressupõe a educação, pelo menos primária, daquele que pretendecom ela sebeneficiar (Sussekind, 1946, p. 11).
\end{abstract}

N este contexto, a programação ofertada pelo S.R.O . destinava-se a: (1) instrução dos trabalhadores analfabetos; (2) realização de atividades recreativas culturais (excursões, escotismo, teatro, cinema, música, biblioteca, torneios e campeonatos esportivos). As atividades recreativas - levando "o homem a uma atividade diversa da que está obrigado no ambiente cotidiano" (Sussekind, 1946, p. 21) - deveriam ser cuidadosamente escolhidas, tendo-se em mente a recuperação da fadiga psicológica e muscular decorrente do trabalho nas máquinas, o condicionamento físico e moral para o trabalho, o preenchimento atrativo do tempo livre e a educação para a tolerância e a passividade. Sussekind dedicou longas passagens do documento à descrição dos benefícios sociais da prática dos jogos, do esporte e do escotismo.

Como explendidamenteacentuou o Professor Lourenço Filho, "a educação física, bem dirigida, podetornar-seamaisautêntica escola de educação moral. 0 jogo constitue excepcional motivação que a moderna pedagogía develançar mão para o êxito da educação plena ou integral. E isto porque? Porquea aprendizagem se opera quando hajaatividadeinteressada, isto é, que se produza de dentro para fóra, como expansão de tendênciaseimpulsosnaturais. 0 jogo suscitatodas ascondições para essa apren dizagem real. Ele oferece ocasião para a prática da solidariedade, da compreensão do valor do grupo, do respeito às regras deumaatividadeconjunta. E isto éeducação cívicano melhor sentido da expressão. A presenta oportunidade para o 


\begin{abstract}
exercício da lealdade, para consigo epara com os outros, parao efforço porfiado no sentido devencer, vencendo-seasi próprio; paraa estima da limpeza do corpo edo espírito; para a modestia epara atolerância; para a disciplina prontae consciente; paraa iniciativa, a coragem, o valor. E tudo isto é educação moral". 0 utrossim, éinegavel queos jogos desportivos aprimoram 0 sentido dejustiça, porque ensinam a obedecer a regra, a acatar disciplinadamente a decisão da autoridade constituída, a reconhecer a derrota ea honrar o adversário digno.

D efáto, conformese expressou o Professor A. C arneiro Leão, "a função primordial da educação na sociedade de hoje é antes ajustar, unir, que diferenciar" (Sussekind, 1946, p. 22-23).
\end{abstract}

A operacionalização desse projeto de conformação da classe operária foi facilitada pelo recurso (1) ao imposto sindical compulsório destinado a finalidades culturais e esportivas e (2) à estrutura sindical implementada com a C.L.T . N o documento escrito em 1946, resta a impressão de que o S.R.O foi um projeto de indivíduos atentos aos problemas dos trabalhadores e encantados com as possibilidades de algumas práticas sociais no que tocava à recuperação da força de trabalho e do aumento da produtividade. No entanto, no segundo texto de Sussekind (1950), de que iremos tratar aqui, aparece claramente a dimensão mundial da preocupação com a contenção da classe operária, considerada em iminência de revolucionar 0 mundo.

\title{
Mudar o sentido para manter o sentido
}

Em D uração do trabalho e repousos remunerados (1950), Sussekind faz uma discussão detalhada, apoiado principalmente em bibliografia internacional, a respeito da necessidade histórica de instituição dos repousos remunerados, além de defender a tutela do tempo livre do trabalhador a fim de garantir 0 alcance dos objetivos pretendidos. 0 autor reconhece a existência de relações econômicas desiguais entre capital e trabalho e trabal ha para dirimir esse conflito em busca do equilíbrio e da justiça social. Assim, a justiça deveria intervir nas relações de trabalho, para evitar o "estado de exploração do mais fraco pelo mais forte" e garantir ao trabalhador o direito de "viver com dignidade", não se limitando a "dar a cada um o que lhe pertença", mas, na medida em que a ordem social permitir, buscando "dar a cada um o que necessita". Advoga que a ordem jurídica não poderia restringir sua ação "à proteção dos direitos políticos e patrimoniais dos cidadãos", mas deveria garantir "o direito à vida, à dignidade e ao bemestar à maioria dos homens" e chama de "D itadura do Capitalismo" o sistema "que nega estes direitos" (Sussekind, 1950, p. 3-4). 
Caberia ao Estado, de acordo com o autor, "conceder" e "conciliar" direitos individuais (definidos como adquirir propriedade, fazer contratos com seus congêneres e formar uma família) e sociais (desfrutar de serviços públicos estabelecidos para seu bem-estar e sua proteção frente aos azares da vida) "em proveito da felicidade do seu povo". Entre os direitos sociais - assim chamados por depender "de modo preponderante, da atividade, boa vontade e iniciativa da sociedade organizada e de seus funcionários" - estão o "direito a um trabalho garantido, a férias remuneradas, à segurança material em casos de velhice ou enfermidade, a um salário que permita viver dignamente e à educação". 0 autor destaca ser "recente [...] a tendência [...] dos sistemas jurídicos objetivarem a proteção simultânea e harmoniosa do patrimônio e do trabalho, sob a égide da Justiça Social" (Sussekind, 1950, p.4-5).

Sussekind discorre sobre o modo como os homens exerciam o trabalho durante a escravidão, a servidão e a I dade M édia e sobre as lutas pela liberdade de trabalho, até conquistar a igualdade de direitos nos contratos de locação de serviços. No entanto, essa conquista teve duração efêmera em virtude do desequilíbrio entre a oferta e a procura de trabal ho - advinda da generalização da máquina -, causando a posição desfavorável do trabalhador no tocante à discussão das condições de trabalho e restando ao trabalhador optar entre "as vis condições de trabal ho que lhes eram oferecidas ou a completa miséria oriunda do desemprego" (Sussekind, 1950, p.5-7).

\begin{abstract}
[...] de nada mais valia a liberdade político-jurídica, porque fal tava a liberdade sócio-econômica, sem a qual o exercício daquela será sempre deturpado. 0 trabalho tornou-se mais penoso e a fadiga decorrente das longas jornadas de trabal ho abalava o sistema nervoso do operário, embrutecendo-Ihe o espírito e enfraquecendo-lhe o corpo. 0 gozo dos prazeres espirituais emateriais da civilização continuava a ser um fruto proibido para o proletariado, porque, embora livre, em faceda ordem jurídica, continuava a ser um escravo do sistema econômico vigorante. Erao estranho eenigmático encontro da pobreza com o progresso, como a recordou $\mathrm{H}$ enry G eorge (Sussekind, 1950, p.7).
\end{abstract}

D iscutindo princípios jurídicos, o autor segue demonstrando a relação de desigualdade que se estabeleceu entre as partes envolvidas nas relações de trabalho: "o princípio da liberdade das partes na celebração dos atos jurídicos tornou possível que a duração da jornada, que não se determinava nos contratos, se elevasse a proporções inumanas", o patrão passou a possuir "um direito ilimitado ao exigir trabalho do operário". 0 "predomínio do liberalismo", cuja doutrina é a "tão decantada liberdade individual e abstenção estatal" levou a 
um "retrocesso na história do trabalho humano". Essa situação converteu o operário em um "instrumento de produção", e o "trabal hador, na sua dignidade fundamental de pessoa humana, não interessava ou não preocupava os chefes industriais daquele período" (Sussekind, 1950, p.8-9).

N o discurso de Sussekind, o liberal ismo e a industrialização aparecem como "as causas das lutas sociais do século XIX". Diz ele:

D estarte, nem a liberdadenem a máquina libertaram o homem. Ao contrário, com elas, não só foram rompidos os obstáculos que a idade e o sexo opunham à jornada extorsiva, como se obscureceram os conceitos de dia e de noite; foram violados todos os postulados de higiene, preocupando-se os capitalistas, no seu afã de ganâncias, apenas em adaptar precipitadamenteo ritmo orgânico do produtor ao ritmo mecânico da máquinacomo esplêndidamente observa ALFREDO PALACIOS (Sussekind, 1950, p. 10).

M as Sussekind ressalta que a "liberdade e a máquina geraram indiretamente o movimento operário e as lutas sociais de que resultou 0 advento do Direito do Trabalho". Foi o alcance da "liberdade política", conquistada com a Revolução Francesa "nas formas muitas vezes viciadas do individualismo, que impulsionou o espírito do homem para a libertação completa e definitiva de todas as algemas" (Rusmano, apud Sussekind, 1950, p.10). No raciocínio que o autor desenvolve, dessa liberdade política resultaria "o direito de associação" e, deste, nasceriam "as uniões e os sindicatos que passaram a reivindicar melhores condições de trabalho, dentre as quais assumia destaque o limite da jornada de trabalho". Citando Charles Gide, o jurista afirma que os socialistas viam na redução da jornada de trabal ho "o meio de emancipar o trabalhador, de o redimir em parte da exploração patronal, de permitir-Ihe a preparação para a luta social e política" (Gide, citado por Sussekind, 1950, p. 10). N a fala de Gide, reproduzida por Sussekind, vemos expressamente o processo de apropriação do discurso dos comunistas e socialistas a fim de fundamentar o projeto burguês de contenção das lutas proletárias, baseado no consenso da necessidade de pacto social:

O soperários lobrigavam nela o meio de trabal har menos, sem redução do seu salário, ao contrário, com possibilidade dealta, graças à rarefação da mão-de-obra causada pela redução do número de horas de trabal ho. M as o que, sobretudo, se deve enxergar é o meio de levantar o nível intelectual, moral eaté físico do operário, asseguran do-Ihe os lazeres necessários para recrear-se segundo a fortesignificação dêstetermo, isto é, para cessar de ser máquina de produção e tornar-se homem (Sussekind, 1950, p.11). 
Evidencia-se o apagamento do projeto comunista de superação da propriedade privada e a reforma desse projeto, traduzida na justiça social, no direito ao repouso remunerado, no direito à elevação cultural, no direito ao lazer. M as de que lazer se fala? Antes de tratar desta questão, no entanto, desejamos destacar que, para Sussekind, a saída para os conflitos entre capital e trabalho se dá pela mediação do Estado e da Justiça. Diz:

Por sua vez, a máquina que criara o problema do excesso da
mão-de-obraetornara mais desumanasas condições detrabalho
- criou também o proletariado, com uma consciência declasse
queaureolou suas lutas pela proteção do trabalho humano. A
realidadesocial, os problemas quesurgiam, a agi tação surda das
massas contra seus exploradores, o interêsseda sociedadecomo
um todo, demonstravam que se tornava necessária uma
percepção jurídica aten den do mais obj etivamente às
necessidades, num justo sentido deequilíbrio. Tal compreensão
jurídica [...] adequada àquela realidade, teria, entretanto, de
fazer passar o individualismo aum plano secundário paracolocar
em maior realceo interesse social. Esseo interêssedo direito no
estabelecimento demedidas que, protegendo os mais débeis,
permitisseque estes se colocassem, graças a essa proteção, no
mesmo plano que os mais poderosos, a fim de que, assim,
pudessem ser iguais perantea lei (Sussekind, 1950, p.11-12).

Trata-se, então, da garantia da igualdade através da "delimitação da autonomia da vontade", através da intervenção do Estado no "ajustamento e execução dos contratos de trabalho". Essa intervenção, "a pouco e pouco", fez surgir "a legislação de proteção ao trabalho humano que constitui, em nossos dias, um dos mais expressivos alicerces da civilização". 0 Estado agiu "para pôr fim ao desequilíbrio produzido pelo choque de interesses entre as forças do Capital e do Trabalho". Como "órgão supremo do direito", tornou-se "instrumento de justiça", "intervindo como representante dos interesses coletivos para conter e reprimir os interesses individuais privados", mantendo o equilíbrio "entre os diversos fatores da produção e, portanto, uma maior repartição das riquezas, base do bem-estar-social". D essa maneira, o Estado agia para "limitar, deformar, destruir a diferença entre classes e grupos, a fazer sobressair o interesse coletivo, tornando relativo o direito individual, limitando seu exercício quando ele contrariasse 0 interesse da sociedade" (Sussekind, 1950, p.12-13).

0 autor identifica, no entanto, um limite nesse esforço de proteção do trabalho humano: "até o Tratado de Versalles a proteção ao trabalho humano desenvolveu-se sob fundamento diverso do que hoje justifica o novo ramo das ciências jurídicas na maioria das nações civilizadas". O que moveu a ação do 
Estado no século XIX foi "o intuito de preservar a capacidade produtiva do homem-máquina e a preocupação de subsistir ante a dramaticidade das lutas sociais que se generalizavam" (Sussekind, 1950, p. 13). Assim, afirma ele:

\begin{abstract}
M esmo nasfasesulteriores desua longa evolução, estapolítica protetora, realizadapelo Estado, nuncaperdeu êssecaráter, nunca deixou deconsiderar o trabal hador senão como um instrumento deprodução, nivelado à materialidade dosoutrosinstrumentos deprodução. Todaa política social orientava-seentão no sentido de um objetivo único, que era a proteção do trabalhador, compreendidano seu sentido estrito, e, por assim dizer, material. $\mathrm{N}$ o fundo e em última análise, o pensamento do Estado era obrigar o patrão a pôr na conservação do operário, isto é, desta máquina viva, dequeêle, patrão, seutilizava, mas dequenão era dono, os mesmos cuidados que punha na conservação das máquinas inanimadas, de que também se utilizava, mas das quais era dono eparaas quais tinha os carinhos naturais detodo proprietário (G eorgesRipert, citado por Sussekind, 1950, p.14).
\end{abstract}

Q ual a mudança que o novo ramo do direito do trabal ho operou na "proteção do trabalho humano"? Para Sussekind, com o Tratado de Versalles entrou em cena a "defesa da dignidade do trabalhador como pessoa humana". 0 autor entende que "tudo quanto podia concorrer para abater, diminuir, inferiorizar 0 trabalhador começou a ser atacado e combatido" com os postulados consagrados naquele tratado, "que consubstanciou os princípios contidos nas encíclicas Rerum N ovarum e Q uadragésimo Ano", escritas respectivamente por Leão XIII e Pio XI. "Sob a ação da nova política social, o trabalhador moderno vive em outro clima moral, em outro ambiente social, com outra decência, outra nobreza, outra consciência do seu valor humano" (Sussekind, 1950, p.14). M as a leitura atenta da argumentação do autor demonstra que se tratava de uma "mudança" idealizada: tratava-se da proibição de sentidos, da proibição do sentido de "objeto" e de "mercadoria" à pessoa humana. U ma proibição que visava val orizar aquilo que a burguesia brasileira tanto desprezava: a classe trabalhadora "desqualificada, incompetente e incapaz" presente no Brasil (Weinstein, 2000). Diz 0 jurista:

0 operário deixa de ser um objeto suscetível de aluguel para constituir-se em colaborador de uma atividade econômica, integrado naunidade jurídica da emprêsa. É que, em face do Tratado deVersalleso trabal ho não pode mais ser considerado umamercadoria. Frenteao contrato detrabalho a desigual dade econômica das partes desaparece, como resultantedainterven ção do Estado nalimitação da vontadedo maisforte. $\mathrm{E}$ o tratamento 
desigual, em havendo desigualdadeeconômica, acarreta, assim a equivalênciajurídica entreos contratanteseobjetiva dignificar o trabal ho humano. Em conseqüência, o trabalho e o salário serão, ao invés demercadoriaepreço, prestação econtraprestação deobrigações contraídas.

O D ireito, quefundavaa ordem jurídicana propriedade, passou ater um fundamento correlato: 0 trabal ho. Socializando-see humanizando-se, passou a garantir a iniciativa ea vontade do indivíduo até onde possam pôr em perigo os alicerces econômicosesociais do regimedemocrático queseuspostulados caracterizam.

Tendo por fim dignificar o trabal ho humano, integrando 0 operário na sociedade, não só como construtor dos seusalicerces, mastambém como partícipe dos seus encantos, desenvolveuse, num crescendo incessante, a legislação de proteção do trabalho, tutelando osinteresses dosoperáriosem todosossetores de sua vida. Para tanto contribuiu decisivamente a ação empreendida pela 0 rganização Internacional do Trabalho, através de suas $C$ onferências, das resoluções do seu C onsel ho de Administração e de suas publicações. Com êsse propósito, conseguiu a 0 .I.T, nosseustrinta eum anosdeexisência, consolidar a estrutura internacional da Justiça Social, analisando, debatendo, divulgando, universalizando e ampliando os preceitos de Versal hes, tal como se pode inferir da D eclaração de Filadélfia de 1944, oriunda de uma sua conferência, equecorporifica os objetivos sociais da época presente (Sussekind, 1950, p. 1415) (grifo nosso).

N essa "nova" ordem jurídica, o trabalho deixaria de ser visto como "mera mercadoria", assumindo "idêntica hierarquia que a liberdade". N a atualidade, para um "constitucionalista ajustado ao ritmo acelerado dos tempos, consiste em tornar possível um regime jurídico e social em que o trabalho seja uma exigência moral - não só econômica - de tal modo que se erija em condição para a dignidade humana". A alteração objetiva dá-se com a inclusão nas constituições de "normas de tutela do trabalhador, restringindo sensivelmente a liberdade contratual" (Sussekind, 1950, p. 16). Para o autor,

[...] com a adoção dêsses salutares preceitos detutela do trabalho, de dignificação do operário e derepressão ao uso ilimitado e abusivo do direito e da liberdade, tornou-se possível o desaparecimento, namaioria dasnaçõescivilizadas, do ambiente quecriara os sub-homens deD OST O IEV SKI, osdramas de VÍTOR HUGO, a ironia deV O LTAIRE eo protesto poético deCAST RO ALVES (Sussekind, 1950, p.17). 
De que modo a política de recreação se insere na visão de mundo de Sussekind? No contexto do discurso otimista do jurista, que diz estar o mundo melhor em razão (1) da valorização e (2) da estruturação de um direito de proteção e tutela do trabalhador, o lazer surgiu como uma conquista do movimento operário - garantida pelo Direito e pelo Estado - que viria a contribuir para a dignificação do homem, na medida em que 0 protegeria da destruição física causada pelo trabalho industrial. A limitação do tempo de trabalho aparecia como pré-requisito para a fruição do lazer, um "princípio que se universaliza visando a proteção do trabal ho humano". M as não havia liberdade para o lazer no projeto de Sussekind. Fazia-se necessário tutelar o trabalhador para que empregasse de modo "conveniente" suas horas de lazer:

Tendo por fundamento razões de ordem biológica, social e econômica, foram tais princípios consagradosatravés dafixação da jornada máxima de trabalho, da estipulação do repouso semanal obrigatório edaimposição dasfériasanuaisremuneradas, esboçando-seaindaa tendência deser orientado eestimulado 0 conveniente emprego das horas de lazer dos trabalhadores (Sussekind, 1950, p.81).

0 que temia o jurista?

Razão assiste[...] ao sociólogo JO ÂO LIRA FILH O , quando assinala que "o acúmulo de atenção compromete a índole, esteriliza o sentimento, desperta inclinações para o vício, arrasta a vontadedeabeberar-seo homem dasfontes derecreio aviltadas pela prostituição. Q uanto maisintensamente trabalha, maior necessidade de evasão necessita o homem para corrigir os males biológicosinerentes ao trabalho (Sussekind, 1950, p.87).

Em seu discurso estava expresso o temor - daqueles que apostam na industrialização - de que a massa de trabalhadores se utilizasse das horas de lazer para degenerar sua condição física, comprometendo a produtividade no trabalho. A redução da jornada e a instituição do repouso remunerado comporiam um projeto de formação de um "novo homem", apto a responder às novas necessidades do mundo do trabalho. A regulamentação dos lazeres visava à formação desse novo homem. No projeto de Sussekind, as horas de lazer deveriam permitir ao trabalhador "desvelos de criação", "ser algo mais". Isto seria impossível para trabalhadores considerados "sem cultura", "despossuídos de educação". No raciocínio desse autor,

Aquêles que empregam suas energias estritamenteno manejo damáquina, terminam por ver-seincapacitados, como apontou 
ARIST ÓTELES, para as mais nobrestarefas da vida, a não ser que desfrutem deum descanso quelhes permitam ser al go mais no mundo do quesimples servidores da máquina. A frustração de sua personalidade, através de largas horas de trabalho fatigante, característico, por exemplo, da primeira partedo século XIX, se evidencia com o examedos seus resultados: oshomens emulheres que regressam para suas casas estão incapacitados para pensar eainda para sentir. Asmáquinas são seus tiranos. $N$ ão tiveram descanso al gum para reconhecer-se no fundo de sua intimidade. Somente conheciam uma vida de fadigas intermináveis. 0 direito a um número razoável de horas de trabal ho éo direito de descobrir uma terra de promissão paraa inteligência(Sussekind, 1950, p. 81-82).

Conquistados a redução da jornada de trabalho e o descanso remunerado, 0 principal obstáculo encontrava-se nos próprios trabalhadores, em sua "debilidade cultural". Tratou-se, então, de "regulamentar o tempo destinado ao descanso", considerado "questão de uma importância inestimável, já que o mal-uso que muitos trabalhadores fazem de suas horas e dias de descanso põem em perigo a obra social e cultural que se desejou iniciar com a regulamentação legal da duração do trabalho" (K rotoschin apud Sussekind, 1950, p.83-84). 0 autor complementa:

$\mathrm{E}$, pelo mesmo diapasão se rege a maioria dos escritores trabal histas, ressaltando, em suasobras, os conceitos emitidos peloscitados sociólogosejuristas.

Como seinfere, portanto, são diversos os finsobjetivados pela instituição dos repousos obrigatórios do trabalhador: - de natureza biológica, eis que visa combater os problemas psicofisiológicosoriundos dafadiga eda excessivaracionalização do serviço;

- decaráter social, por isto que possibilita ao trabalhador viver, como ser humano, na coletividadea que pertence, gozando os prazeres materiais e espirituais criados pela civilização, entregando-seà prática das atividades recreativas, culturais ou físicas, aprimorando seus conhecimentoseconvivendo ${ }_{2}$ enfim, com suafamília;

- de índole econômica, porquanto restringe o desemprego e acarreta, pelo combate à fadiga, um rendimento superior na execução do trabalho.

E se esses são, em verdade, os fins colimados pelos repousos obrigatórios do trabal hador, certo équeos seus fundamentos são absolutamente científicos, profundamente humanos e remarcadamentetécnicos(Sussekind, 1950, p. 85). 
A instituição dos lazeres, tal como as leis trabalhistas e a sindicalização, foi uma imposição de Estado, carregada de decisões prévias do que poderia e do que não poderia ser realizado. 0 tempo de lazer passou a ser o novo locus do embate entre capital e trabalho: terás tempo livre desde que pratiques atividades que tragam benefício ao capital! As estratégias geradas pelos trabalhadores para fugir dessa invasão de sua vida privada são certamente algo instigante a investigar. Em várias passagens identificamos essa preocupação em ditar o que caberia ao tempo de lazer:

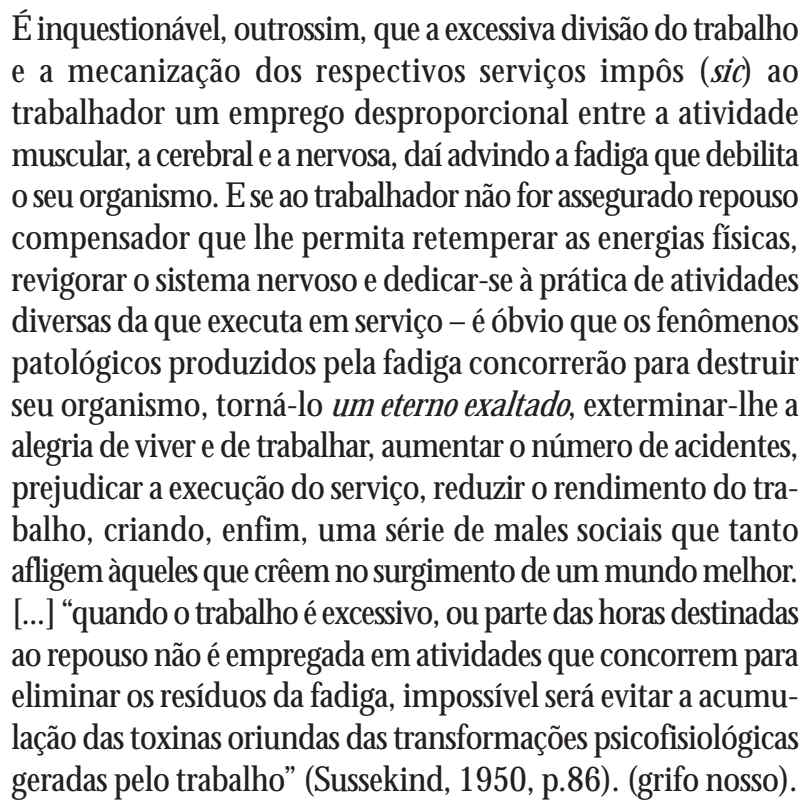

"Um mundo melhor" seria um mundo onde as relações contratuais entre capital e trabalho estivessem equilibradas, sem o risco da insatisfação dos operários e das assustadoras mobilizações nas ruas, sem o risco das perigosas toxinas acumuladas no organismo, que abalam e tensionam o humor, preparando 0 conflito. 0 projeto de recreação para o trabalhador veio acoplar-se ao projeto de industrialização. Foi a forma que o capital encontrou para apossar-se do tempo livre do trabalhador, convertendo-o em tempo útil ao processo produtivo.

0 aproveitamento adequado dashoras delazer do trabalhador e de sua família constitui corolário sem o qual não poderão atingir seus objetivosos repousos diários, semanaiseanuaisque as leis ou convenções tornarem obrigatórios na execução do contrato detrabal ho.

Conseqüentemente, incumbe ao Estado M oderno - sem prejuízo das atividades das organizações sindicais e de 
empregadores - estimular e facilitar aos trabalhadores 0 adequado aproveitamento de suas horas de repouso, proporcionando-Ihe (sic) meios para se dedicarem a funções recreativas, culturais ou desportivas, para o queéimportante que se atenda à natureza do serviço realizado nas horas de trabalho, ao biotipo eàstendências do trabalhador.

Com efeito, "enquanto queos desportos ou os exercíciosfísicos são indispen sáveis para eliminar a fadiga dos que exercem suas funçõescom grandeatividadecerebral ou em serviço denatureza sedentária, de mero contrôleemecanismo ou demonótona e continuada atenção, servem os sistemas de recreação cultural para pôr têrmo à fadiga dos que trabal ham em serviços que extenuam os músculos e não exigem o emprêgo das funções cerebrais"s.

Trabalho, recreação e repouso - eis a fórmula ideal para a existência feliz do homem que produz (Sussekind, 1950, p.555-556).

N o capítulo "O aproveitamento das horas de lazer como corolário dos repousos obrigatórios", referindo-se à "Ação internacional em favor dos lazeres operários", Sussekind relata várias ações e eventos internacionais voltados para uma política mundial de ocupação do tempo livre do trabalhador. Um projeto de racionalização do tempo livre foi estruturado em organismos especificamente criados com esta finalidade dentro da OIT. A burguesia organizava-se para evitar a expansão do bloco socialista em consolidação.

\section{Considerações provisórias}

O S.R.O . surgiu no cenário nacional como parte de um projeto mais amplo de contenção preventiva do processo de organização da classe trabalhadora no Brasil, visto como uma necessidade do projeto de consolidação de uma indústria forte. D e certa forma, o S.R.O. foi uma espécie de projeto piloto do que viria a ser, mais tarde, a parte do Sistema "S" destinada à prestação de serviços de lazer - os Serviços Sociais da Indústria e do Comércio (SESI e SESC). Foi um movimento histórico de retomada da política de "pão e circo", unido ao projeto mundial de contenção da luta de classes, a fim de evitar a formação da classe operária no Brasil.

A produção do conhecimento voltada para o entendimento e para a delimitação do lazer iniciou-se nesse período histórico, como parte do processo (1) de

8. Refereência no Original: "ARNALDO SUSSEKIND - Recreação Operária, pág. 8." (SUSSEKIND, 1950, p. 556). 
revolução burguesa que, no Brasil, deu-se pelo alto, ou, ainda, como revolução passiva; (2) de construção da hegemonia burguesa no Brasil (Braga, 2005). A nosso ver, a análise histórica da produção do conhecimento em recreação e lazer no Brasil deve ocorrer considerando-se a dinâmica social que a gera como parte dos processos de teorização do real. Independente de poderem dar conta ou não da dinâmica em que estão inscritos, esses textos refletem os embates históricos travados na sociedade, os embates entre os interesses dos proprietários dos meios de produção e os interesses dos que vivem da venda de sua força de trabalho.

A revisão bibliográfica e histórica dessa produção deve guiar-se pela preocupação de compreender (1) a produção de idéias como parte constitutiva dos embates travados no modo de produção da existência; (2) o intelectual como autor de um discurso que expressa posições ante os conflitos, os embates ideológicos e os embates de interesses existentes na realidade objetiva e no próprio processo de produção da existência. D esde o seu início, a produção do conhecimento referente aos estudos do lazer no Brasil tem expressado os conflitos de posição e os embates de interesse na definição dos rumos que a formação da subjetividade da classe trabalhadora deveria tomar. $\mathrm{N}$ ão se trata de afirmar que a classe trabalhadora acatou passivamente o projeto da burguesia. Trata-se, apenas, de reafirmar categoricamente, juntamente com outros trabalhos, que a burguesia possuía, sim, um projeto de classe - ainda que houvesse discordância em seu interior - que escorreu para lugares aparentemente inusitados, como a produção do projeto de recreação operária conduzido por Arnaldo Sussekind.

\section{Referências bibliográficas}

BRAGA, L. S. U ma civilização sem alma? Educação erevolução passiva. 2005. D issertação (M estrado em Educação). UniversidadeEstadual de Campinas, Campinas, SP. f.58-102.

FRAN CO , R. V. Brevehistórico da justiça edo direito do trabalho no Brasil. Tribunal Superior do Trabalho. Serviço deC onservação eArquivo. D isponível em: «http://www.tst.gov.br/>. Acesso em 19 jul. 2006.

GAN D RA, E. Á.; SILVA, A. J.; N ASCIM EN TO , M . I M .. A orientação político-educacional no populismo ea evolução da estratégia liberal para conter a mobilização operária. Revista H IST ED BR O n-line, Campinas, n.19, p.117-133, set.2005.

GOM ES, A. C.; D 'ARAÚJO , M . C. Entrevista com Arnaldo Sussekind. EstudosH istóricos, Rio de Janeiro, v.6, n.11, p.113-127, 1993. D isponível em: http://www.cpdoc.fgv.br/revista/ arq/117.pdf. Acesso em: 18 de set. 2005.

GO M ES, C. L. Lazer etrabalho no contexto urbano: reflexões sobre os "clubes de menores operários" (1937-1947). In: M Ü LLER, A. da CO STA, L. Lazer e trabalho: um único ou múlti plosol hares? Santa C ruz do Sul: ED U N ISC, 2003a. p.2-44. 
GOM ES, C. L. Significados da recreação e lazer no Brasil: reflexões a partir da análise de experiências institucionais (1926-1964). 2003b. 322f. Tese (D outorado em Educação). U niversidadeF ederal de M inas Gerais, Belo H orizonte, M G .

H O BSBAW M , E. A era dosimpérios(1875-1914). 8.ed. São Paulo: Paz eTerra, 2003.

H O BSBAW M , E. Era dosextremos: o breveséculo XX. (1914-1991). São Paulo: Companhia dasLetras, 1995.

M ARCASSA, L. A invenção do lazer: educação, cultura etempo livrena cidade de São Paulo. (1888-1935). 2002. 204f. D issertação (M estrado em Educação Brasileira). U niversidade Federal deG oiás, G oiânia, GO .

M ASCAREN H AS, F. Entre o ócio e o negócio: teses acerca da anatomia do lazer. 2005. 307 f. Tese (D outorado em Educação Física) - U niversidade Estadual de Campinas, C ampinas. 2005.

N OTÍCIASD O TRIBU N AL SU PERIOR DO TRABALH O (Brasil). Tribunal Superior do Trabalho. Arnaldo Sussekind acredita em pacto social no governo Lula. Publicado em 22/12/ 2002. D isponível em: «ttp://www.tst. gov.br/noticias/>. Acesso em: 11 set. 2005.

PICH ELI, V. O ID ORT enquanto proposta educaci onal no contexto de formação da hegemonia burguesa no Brasil 1930-1945. 1997. D issertação (M estrado em Educação). U niversidade Estadual de Campinas, Campinas, SP.

SO D RÉ, F. Asnecessidades dosoperários brasileiros. Revista deEstudos Brasileiros, Anno I, n.1, p.66-82, jul./ago. 1938.

SU SSEKIN D , A. A chave do sucesso: Arnaldo Sussekind - um cidadão ilustre. (Entrevista) Revista Prática Jurídica, Editora Consulex, Anexo III, n.30, 30/09/2004. p.6-9.

SU SSEKIN D , A. Convençõesda O IT . São Paulo: LTR, 1994.

SU SSEKIN D , A. D uração do trabalho erepousosremunerados. Rio de aneiro: Livraria Freitas Bastos, S.A., 1950.

SU SSEKIN D , A. Recreação operária. Rio de Janeiro: M inistério do Trabal ho, Indústria e Comércio, 1948.

SU SSEKIN D , A. Trabalho eRecreação: fundamentos, organização e real izações do Serviço de Recreação O perária. Rio de Janeiro: M inistério do Trabalho Indústriae C omércio, 1946.

SU SSEKIN D , Arnaldo; M ARI N H O , Inezil Penna; GÓ ES, O swaldo. M anual de Recreação: orientação dos lazeres do trabalhador. Rio de Janeiro: M inistério do Trabalho, Indústria e Comércio, 1952.

W EIN ST EIN , B. (Re) Formação da dasse trabalhadora no Brasil (1920-1964). São Paulo: Cortez, CD PAH -IFAN - UniversidadeSão Francisco, 2000.

Recebido em 31 deoutubro de2006 eaprovado em 08 denovembro de2007. 